\title{
Study on the Relationship between Entrepreneurship Intellectual Capital and the Enterprise Performance
}

\author{
Yen-Jo Kiang ${ }^{1}$, Yu Cao ${ }^{2}$, Wei Yue ${ }^{2}$ and Ke-Chiun Chang ${ }^{1,3 *}$
}

${ }^{1}$ Department of Business Administration, CTBC Financial Management College, Tainan, Taiwan

${ }^{2}$ Business School, Central South University, Changsha, China

${ }^{3}$ School of Economics and Management, Wuhan University, Wuhan, China

\begin{abstract}
This paper empirically studies the relationship between entrepreneurship intellectual capital and the enterprise performance in China through questionnaire survey. This result shows that entrepreneurship intellectual capital has significant impact on enterprise performance. However, different dimension of entrepreneurship intellectual capital makes different driving effect. Entrepreneurship innovation capital, entrepreneurship human capital and entrepreneurship social capital have positive effects on competitive and potential performance, while entrepreneurship structural capital has significant positive effect on competitive performance but no significant impact on potential performance. The value of entrepreneurship intellectual capital is partly explained, and some suggestions of the accumulation of entrepreneurship intellectual capital are given.
\end{abstract}

Keywords: Entrepreneurship; Intellectual capital; Human capital; Enterprise performance; China

\section{Introduction}

In the age of knowledge-based economy, knowledge has become the enterprises' most important production factor and contributes more and more in the process of enterprise value creation. Intellectual capital is now "the third resource" which promotes the development of enterprise besides the financial capital and labor capital [1-3]. The economic growth depends more directly on the investment and operations of intellectual capital. Entrepreneur enterprise performance informs us of the extent towards a specific target, and also reflects whether the enterprise can be deemed successful. According to the theory of intellectual capital, entrepreneurship intellectual capital contains several dimensions. We would like to address the questions regarding how much intellectual capital increasingly becoming the core competence contributes to entrepreneurship enterprise performance. This also raises the issue about which dimension of intellectual capital does entrepreneurship enterprise performance depends on? A precise conclusion should be based on thorough analysis. So it is necessary for us to research the relationship between entrepreneurship intellectual capital and enterprise performance.

To start with, this paper will introduce relative researches on the notion and elements of intellectual capital and the relationship between intellectual capital and enterprise performance in previous studies. In order to give useful suggestions of enhancing the intellectual capital management, we do further study on the constituent elements of intellectual capital and empirical research on the relationship between entrepreneurship intellectual capital and enterprise performance by questionnaire based on the latest theory of intellectual capital.

\section{Literature Review}

Intellectual capital poses as valuable knowledge that can make profit for knowledge-based enterprises [4], it is the part that where market value of a company above its book value [5]. Hidden in the knowledge, existing and spreading in the form of knowledge, intellectual capital is the prepayment value which has value appreciation accumulated during the production and management of enterprises [6].

Stewart [7] divides the intellectual capital into human, structural and consumer capital. However, Edvinsson and Malone [5] divide it into two categories: human capital and structural capital. And Roos et al. [8] subdivides structural capital into relational, organizational, innovational and developmental capital. In China, Qiu et al. [9] partitions intellectual capital into four parts including human, structural, technological and market capital. Fan [10] splits it into five levels, that is human, organizational, technological, market and social capital. Zhang and Wang [11] divide it into human, structural, social and innovational capital and also have established and verified the intellectual capital structure of high-tech enterprise by multi-level questionnaire measurement.

Based on the prevalent view of the current academic, intellectual capital contains four parts in general, that is human, structural, social and innovational capital. Human capital is the competence knowledge of an enterprise's management team, including their education background, work and industry experience, relevant training and so on. Structural capital is the internal structure knowledge of an enterprise, including organizational culture, business process, development strategy and so forth. Social capital is reflected by the knowledge of the relationship between enterprises and its external environment. Nahapiet and Ghoshal [12] define social capital of enterprise as "available actual and potential resources embedded in and also derived from relation network of individual or social unit", that is enterprise owned knowledge about market channels and enterprise established client network, mainly including the relationship amongst entrepreneurship enterprises and clients, partners, educational institutions, governments and so on. Reflecting the innovation ability

*Corresponding author: Ke-Chiun Chang, Department of Business Administration, CTBC Financial Management College, Tainan, Taiwan, Tel: 862768753177; E-mail: dr.chang@whu.edu.cn; kechiun@gmail.com

Received August 05, 2016; Accepted October 22, 2016; Published October 29 2016

Citation: Kiang YJ, Cao Y, Yue W, Chang KC (2016) Study on the Relationship between Entrepreneurship Intellectual Capital and the Enterprise Performance. Bus Eco J 7: 256. doi: 10.4172/2151-6219.1000256

Copyright: ( 2016 Kiang YJ, et al. This is an open-access article distributed under the terms of the Creative Commons Attribution License, which permits unrestricted use, distribution, and reproduction in any medium, provided the original author and source are credited. 
of an entrepreneurship enterprise, Innovation capital mainly contains $\mathrm{R} \& \mathrm{D}$ funds, the results of technology-innovation, and policies of innovation incentive and so on.

Intellectual capital has been a hot issue for a long time in academic circle. And previous studies concentrate on the definition, classification and measuring of intellectual capital, recently, some scholars empirical study on the relationship between the intellectual capital and enterprise performance. Bontis [13], Bassi and Van Bure [14], and Chen et al. [15] hold the view that intellectual capital has an important effect on enterprise performance. Bontis [13] points out that intellectual capital has a significant positive impact on enterprise performance in the measurement model of intellectual capital without considering industrial fields.

Petty and Guthrie [16] indicate that the next mission of the research on intellectual capital is needed whereby empirical tests legitimize the study of this construct and provide more robust evidence on which to build. Shiu [17] use Value Added Intellectual Coefficient model for measuring the value creation efficiency, and find that the index of VAIC of Taiwan listed technologies firms had a significantly positive correlation with profitability (ROA) and market valuation (MB), and a negative correlation with productivity (ATO). Li and Liu [18] make an analysis of the intellectual capital and enterprise performance of the listed companies in China with CIV model, and the result shows that intellectual capital has a positive correlation with net profit and net cash flow. Tan and Plowman [19] has an Asian focus, and draws on data from 150 publicly listed companies on the Singapore Exchange, empirical study elements of IC and company performance. And he finds that intellectual capital and company performance are positively related. Hsu and Fang [20] indicates that human capital and relational capital actually improve new product development performance, but managers should pay attention to possibly negative effects of structural capital on new product development performance. Sharabati et al. [21] empirically test the relationship between intellectual capital and firm performance in the pharmaceutical sector of Jordan, and find the intellectual capital variables and sub-variables had a substantive and significant relationship with business performance.

In this paper, we design a questionnaire survey to collect information on enterprise grass-roots and middle-senior management of the entrepreneurship corporations. With the help of SPSS, we hold an empirical study on the relationship between entrepreneurship intellectual capital and enterprise performance and give some suggestions about entrepreneurship intellectual capital accumulation in order to improve enterprise performance.

\section{Methodology and Measurement}

\section{Sample and data collection}

The Questionnaire method is a method of collecting research information or data from research objects with writing form that contains a set of strictly designed test items or questions. As questionnaire method is applicable to wide range of research issues, and can get all data with fewer errors and prejudice-avoid systematically, so based on documentation method and conversation method, this paper uses questionnaire method as the main method to research the relationship between intellectual capital and enterprise performance.

In this research, representative randomized sampling is used to choose samples, which will be more pertinent and effective. During the survey, we pay more attention to sci-tech pioneering center and the ones belonging to the high tech area, and emphasis that the samples should be cross-regional, cross-industry, different characteristic enterprises contained, and so on. We sent out 1000 questionnaires to entrepreneur enterprises of sci-tech pioneering center in Guangzhou, Shenzhen, Suzhou, Hangzhou, Nanjing, Chongqing, Wuhan, Zhengzhou, Changsha, Sian, Changchun, Shenyang and so on in China. In the end, we received 891 questionnaires and there is 803 validity questionnaires removed out 88 invalidity questionnaires, the effective recovery rate is $80.3 \%$. The questionnaires are mainly finished by grass-roots and middle-senior managers to reflect characters of entrepreneur enterprise.

\section{Measurement}

Entrepreneurship intellectual capital: Based on the content of semi-structured interview and some literatures about intellectual capital, we get the measure table of entrepreneurship intellectual capital by drawing up, trial-test and revision. The questionnaire contains eighteen issues such as the number of members with technical background in the team, making a long-term development strategy and carrying it out, the core technology is unique and can't be replaced, and so on. All the issues will be evaluated by Likert scale, and mark from 1 to 5 points to reflect strongly disagree, disagree, neither agree nor disagree, agree, strongly agree respectively.

Entrepreneurship enterprise performance: Organization performance can be evaluated in subjective and objective way. In this paper, we take the relative-performance measurement method of subjective evaluation as our measuring method and the using of absolute financial performance can certainly increasing the research reliability. However, in the view of most Asian countries, it is quite hard to get exact data of absolute financial performance, so most empirical researches in China prefer relative financial performance. There is empirical researches show that absolute financial performance and relative financial performance have strong correlation ship. The reasons of taking subjective evaluation method are based on the following ones. Firstly, it is quite hard for us to get the actual data of an enterprise; secondly, it will go against to the cultivation of core competence and the establishment of long-term competitive advantage if more attention is paid to short-term financial results rather than long-term development of a company. Scholars think the data of absolute financial are impacted by many relative factors. So we think it may lead to misunderstanding and have impact on the quality of the original data by directly comparison of different enterprises' objective financial data.

At first, we should make sure of the operational definition of entrepreneurial performance, and decide to measure it by subjective performance indexes. Based on scales, we revise and make our own questionnaire as required in this paper. The main content of the scale contains the growth of market share, the growth of sales revenue, innovation ability and ability of R\&D in high-tech entrepreneurship enterprise. Issues of samples contain main business of the company increased strongly compared to last year, technological innovation has a higher growth rate and so on, and interviewers are asked to choose right answers from Likert scale according to their fact.

\section{Empirical Results}

\section{Entrepreneurship intellectual capital scale analysis}

Factor analysis requires that the ratio of samples and variables should be higher than 5:1, the number of samples should be higher than 100, and the KMO should not lower than 0.5. In this paper, the ratio of samples and variables is nearly $45: 1$, the number of samples is 
803 , and $\mathrm{KMO}=0.905$, which is much higher than 0.5 , so the data are suitable for factor analysis.

The exploratory factor analysis is conducted to the entrepreneurship intellectual capital questionnaire by principal component factor analysis and varimax rotation to distinguish the creation processes of different intellectual capitals with extracted factors. The extract number is determined by Kaiser Standard and KMO Text Methods. Four key factors with eigenvalues greater than 1 and factor loadings greater than 0.5 are extracted. In the end, we get a measure table of entrepreneurship intellectual capital which contains 17items and have 4 factors, each of the factor consists of 5 items, 4 items, 4 items, 4 items respectively. The results of factor analysis are listed in Table 1.

The results of factor analysis indicate that 17 variables all have high load under a certain primary factor and the structure of them is clear, which is well matched to our thinking and assuming. It is also consistent with the results of interviewing indicated that the questionnaire have a good construct validity. According to factor analysis, entrepreneurship intellectual capital can be divided into entrepreneurship structural capital, entrepreneurship innovation capital, entrepreneurship human capital and entrepreneurship social capital, and this four factors together account for $58.4 \%$ of the total variance. In which entrepreneurship structural capital accounts for $18.5 \%$ of variance while others accounts for $15.0 \%, 13.6 \%, 11.4 \%$ of variance respectively. The coefficient of internal consistency of the 4 factors are $0.80,0.78,0.75$ and 0.64 respectively. The first three factors show a good internal consistency. Though the coefficient of internal consistency of the forth factor is not high enough, it is still higher than 0.6 and the internal consistency coefficient of the table is 0.90 , which indicates high homogeneity reliability of the questionnaire. Seeing from 4 factors account for variance, entrepreneurship structural capital and innovation capital accounts more for entrepreneurship intellectual capital, which display a marked difference between entrepreneurship

structural capital and entrepreneurship innovation capital in different entrepreneurship enterprises (Table 1).

\section{Entrepreneurship enterprise performance scale analysis}

In this paper, the ratio of samples and variables is nearly $45: 1$, the number of samples is 803 , and KMO is 0.845 , which is much higher than 0.5 , so the data are suitable for factor analysis.

The exploratory factor analysis is conducted to the entrepreneurship intellectual capital questionnaire by principal component factor analysis and Varimax rotation to distinguish the creation processes of different intellectual capitals with extracted factors. The extract number is determined by Kaiser Standard and KMO Text Methods. Two key factors with eigenvalues greater than 1 and factor loadings greater than 0.5 are extracted. Additional, some subjects cross loading on two dimensions both with high weights are deleted, such as V59, whose cross loading on two dimensions are 0.582 and 0.411 respectively. In the end, we get an enterprise performance measure table contains 8 items which is two dimensions with 4 items each. The results of factor analysis are listed in Table 2.

According to Table 2, the extracted factors are match to our thinking and assuming about entrepreneurship enterprise performance. The results of factor analysis indicate that entrepreneurship corporation performance can be divided into competitive performance and potential performance which together account for $60.1 \%$ of variance, and while competitive performance accounts for $30.6 \%$ of variance, potential performance accounts for $29.6 \%$. The coefficient of internal consistency of the 2 factors are 0.79 and 0.75 respectively, and the internal consistency coefficient of the table is 0.84 , which indicates high homogeneity reliability of the questionnaire (Table 2 ).

\section{Regression analysis}

In this research, we will test the impact of entrepreneurship

\begin{tabular}{l|l|l|l} 
Factor 1 & Factor 2 & Factor 3 & Factor 4
\end{tabular}

Measure Item

Factor 1: entrepreneurship structural capital $\alpha=0.80$

V26 standardize business process, monitoring products quality and work efficiency

V24 formulate a long-term developing strategy and put it into practice

V25 marketing channels meet the needs of marketing demanded

V27 shaping the organizational culture to guide and influence staff development

V23 expanding new industries and markets immediately is quite important

Factor 2: entrepreneurship innovation capital $\alpha=0.78$

V33 have unique core technology which cannot be replaced by others

V34 have enough $R$ \& D staff with high quantity and quality

V35 organization structure and process in the corporation motivate innovation

V32 good at technology and have high input of R\&D

0.719

employees

V22 the team members keep up with the latest developments in their fields

V18 have enough employees with technical background

V20 entrepreneurship team is good at innovation management

Factor 4:entrepreneurship social capital $\alpha=0.64$

V29 build up technical cooperation with universities and R\&D institutions

V30 cooperated with partners in products and technology

V31 keep good relationship with governments and communities

V28 keep communication with customers to improve products and services

Eigenvalue

$\%$ of variance

Cumulative $\%$

\begin{tabular}{|l|l|}
\hline 0.719 & 0.173 \\
\hline 0.654 & 0.165 \\
\hline 0.622 & 0.194 \\
\hline 0.618 & 0.253 \\
\hline 0.599 & -0.003 \\
\hline
\end{tabular}

0.096

0.171

0.446

0.100

\begin{tabular}{|l|l|}
\hline 0.786 \\
\hline 0.771 \\
\hline 0.634 \\
\hline 0.576 \\
\hline
\end{tabular}

\begin{tabular}{|c|c|c|c|}
\hline 0.285 & 0.053 & 0.696 & 0.220 \\
\hline 0.273 & 0.197 & 0.663 & -0.051 \\
\hline-0.240 & 0.335 & 0.633 & 0.364 \\
\hline 0.321 & 0.229 & 0.568 & 0.213 \\
\hline \multicolumn{3}{|l|}{} \\
\hline 0.035 & 0.356 & 0.100 & 0.678 \\
\hline 0.482 & 0.323 & 0.234 & 0.591 \\
\hline 0.480 & -0.040 & 0.112 & 0.508 \\
\hline 3.15 & -0.032 & 0.108 & 0.504 \\
\hline 18.5 & 2.54 & 2.30 & 1.94 \\
\hline 18.5 & 15.0 & 13.6 & 11.4 \\
\hline
\end{tabular}

0.027

\begin{tabular}{|l|l|}
\hline 0.156 & 0.027 \\
\hline 0.388 & 0.105 \\
\hline
\end{tabular}

\begin{tabular}{l|l}
0.146 & 0.123
\end{tabular}

\begin{tabular}{l|l}
0.053 & 0.335
\end{tabular}

\begin{tabular}{l|l}
0.503 & -0.069
\end{tabular}

\begin{tabular}{l|l}
0.246 & 0.073
\end{tabular}

\begin{tabular}{l|l}
0.221 & 0.174
\end{tabular}

\begin{tabular}{l|l}
0.080 & 0.121
\end{tabular}

\begin{tabular}{l|l}
0.024 & 0.443
\end{tabular}

$0.696-100$

\begin{tabular}{|l|r|}
\hline 0.663 & -0.051 \\
\hline 0.633 & 0.364 \\
\hline 0.568 & 0.213 \\
\hline & \\
\hline 0.100 & 0.678 \\
\hline 0.234 & 0.591 \\
\hline 0.112 & 0.508 \\
\hline 0.108 & 0.504 \\
\hline 2.30 & 1.94 \\
\hline 13.6 & 11.4 \\
\hline 47.0 & 58.4 \\
\hline
\end{tabular}

Table 1: Factor Analysis Result of Entrepreneurship Intellectual Capital Scale ( $\mathrm{N}=803)$. 


\section{Measure Item}

Factor 1 Factor 2

Factor 1: competitive performance $\alpha=0.79$

V56 turnover of total assets is good

V55 profit margin of main business is good

$0.801 \quad 0.135$

V57 main business increase quickly compare to last year

V58 growth of total assets is much higher

Factor 2: potential performance $\alpha=0.75$

V62 growth of technical innovation is more quickly

V63 the number of new products is more

V61 growth of the number of employees is more quickly

V60 growth of the number of customers is more quickly

0.784

0.729

0.154

$0.632 \quad 0.391$

Eigenvalue

$\%$ of variance

Cumulative $\%$

\begin{tabular}{|c|c|}
\hline 0.181 & 0.794 \\
\hline 0.112 & 0.768 \\
\hline 0.279 & 0.666 \\
\hline 0.369 & 0.632 \\
\hline 2.45 & 2.36 \\
\hline 30.6 & 29.6 \\
\hline 30.6 & 60.1 \\
\hline
\end{tabular}

Table 2: Factor Analysis Result of Entrepreneur Enterprise Performance ( $N=803)$.

\begin{tabular}{|c|c|c|c|c|}
\hline \multirow[t]{2}{*}{ Independent } & \multicolumn{2}{|c|}{ Competitive Performance } & \multicolumn{2}{|c|}{ Potential Performance } \\
\hline & $\beta$ & $\mathbf{T}$ & $\beta$ & $\mathbf{T}$ \\
\hline $\begin{array}{l}\text { Entrepreneurship } \\
\text { structural capital }\end{array}$ & 0.263 & $7.919^{* * *}$ & 0.005 & 0.172 \\
\hline $\begin{array}{l}\text { Entrepreneurship } \\
\text { innovation capital }\end{array}$ & 0.164 & $4.933^{* \star *}$ & 0.427 & $14.059^{\star * *}$ \\
\hline $\begin{array}{l}\text { Entrepreneurship } \\
\text { human capital }\end{array}$ & 0.162 & $4.890^{\star \star *}$ & 0.208 & $6.838^{\star * *}$ \\
\hline $\begin{array}{l}\text { Entrepreneur ship } \\
\text { social capital }\end{array}$ & 0.088 & $2.655^{\star \star}$ & 0.210 & $6.918^{* * *}$ \\
\hline Adjusted $\mathrm{R}^{2}$ & \multicolumn{2}{|c|}{0.126} & \multicolumn{2}{|c|}{0.267} \\
\hline F Value & \multicolumn{2}{|c|}{$29.546^{* * *}$} & \multicolumn{2}{|c|}{$73.449^{* * *}$} \\
\hline
\end{tabular}

Note: ${ }^{*} p<0.05,{ }^{* *}<0.01,{ }^{* * *}<0.001, \beta$ is the standardized regression coefficients

Table 3: Results of Multiple Regression Analysis $(\mathrm{N}=803)$

intellectual capital on entrepreneurship enterprise performance. A multiple regression model is made by executing a regression analysis, taking the 4 factors of entrepreneurship intellectual capital as independents, taking the 2 factors of entrepreneurship enterprise performance as dependents. The results of multiple regression analysis are listed in Table 3.

The results of multiple regression analysis shown in Table 3 indicated that different factors of entrepreneurship intellectual capital have different impact on entrepreneurship enterprise performance. Entrepreneurship structural capital, entrepreneurship innovation capital, entrepreneurship human capital and entrepreneurship social capital have significant positive impact on competitive performance, meanwhile, the last three primary factors have significant positive impact on potential performance, but the entrepreneur structural capital has no significant impact on entrepreneur potential performance. The results of statistics indicate that entrepreneurship intellectual capital have positive impact on entrepreneurship enterprise performance, and different factors of entrepreneurship intellectual capital have different effect on entrepreneurship enterprise performance (Table 3 ).

\section{Variance analysis}

We take the 4 factors of entrepreneurship intellectual capital, which are entrepreneurship structural capital, entrepreneurship innovation capital, entrepreneurship human capital and entrepreneurship social capital as cluster variables. On the condition of cluster numbers, we use K-mean cluster method to analyze the entire sample and divide the sample into two groups according to 4 factors of entrepreneurship intellectual capital, the high score group represents the high entrepreneurship intellectual capital while the low score group represents the low entrepreneurship intellectual capital. The results of cluster analysis are listed in Table 4.

According to the results of clustering analysis, single factor analysis of variance is applied to analyze entrepreneurship enterprise performance of the two groups. The results are listed in Table 5.

The result of variance analysis indicates that the enterprise performance in the high score group is significantly better than that in the low score group, which reflects in both competitive performance and potential performance. So we can see that there is significant difference in entrepreneurship enterprise performance with different entrepreneurship intellectual capital (Tables 4 and 5).

\section{Conclusions and Implications}

\section{Conclusion}

From the analysis results of the questionnaire surveys we can see that, the entrepreneurship structural capital, the entrepreneurship innovation capital, the entrepreneurship human capital and the entrepreneurship social capital are the four primary dimensions of entrepreneurship intellectual capital, and the first two factors have a greater degree of impact on entrepreneurship intellectual capital. Results of regression analysis show that all the four factors have positive effect on competitive performance, while only the last three ones have significantly positive effects on potential performance which shows that the entrepreneurship intellectual capital has positive effect on entrepreneurship performance, and different dimension of entrepreneurship intellectual capital has different driving effect on entrepreneurship performance. The results of analysis of variance show that, the competitive performance and potential performance of entrepreneurship enterprise with a high entrepreneurship intellectual capital are much better than that with a low entrepreneurship intellectual capital.

\section{Implications}

It is a key factor to accumulate entrepreneurship intellectual capital for entrepreneurship enterprises to raise their competitiveness. The results of this paper indicate that the entrepreneurship intellectual capital is not an inane notion, and can be embodied by the

\begin{tabular}{|l|c|c|}
\hline Factors of & High Score Group & Low Score Group \\
\cline { 2 - 3 } $\begin{array}{l}\text { Entrepreneurship } \\
\text { Intellectual Capital }\end{array}$ & Mean value of clustering & Mean value of clustering \\
\hline Structural capital & 0.00044 & -0.00070 \\
\hline Innovation capital & 0.10663 & -0.17137 \\
\hline Human capital & 0.46304 & -0.74416 \\
\hline Social capital & 0.42231 & -0.67871 \\
\hline N & 495 & 308 \\
\hline
\end{tabular}

Table 4: Cluster Analysis of Entrepreneurship Intellectual Capital $(\mathrm{N}=803)$.

\begin{tabular}{|c|c|c|c|c|c|}
\hline & \multirow[t]{2}{*}{$\mathbf{N}$} & \multicolumn{2}{|c|}{$\begin{array}{l}\text { Competitive } \\
\text { Performance }\end{array}$} & \multicolumn{2}{|c|}{$\begin{array}{c}\text { Potential } \\
\text { Performance }\end{array}$} \\
\hline & & M & SD & M & SD \\
\hline \multicolumn{6}{|c|}{ Entrepreneurship Intellectual Capital } \\
\hline High score group & 490 & 0.152 & 0.963 & 0.214 & 0.927 \\
\hline Low score group & 305 & -0.244 & 1.011 & -.343 & 1.019 \\
\hline F value & & \multicolumn{2}{|c|}{$30.631^{* * *}$} & \multicolumn{2}{|c|}{$62.872^{\star \star \star}$} \\
\hline $\begin{array}{l}\text { Group comparison } \\
\text { (Duncan testing) }\end{array}$ & & \multicolumn{2}{|c|}{$1>2$} & \multicolumn{2}{|c|}{$1>2$} \\
\hline
\end{tabular}

Note: ${ }^{*} \mathrm{p}<0.05,{ }^{* *}<0.01,{ }^{* * *}<0.001$

Table 5: Results of Multivariate Analysis of Variance $(\mathrm{N}=803)$. 
Citation: Kiang YJ, Cao Y, Yue W, Chang KC (2016) Study on the Relationship between Entrepreneurship Intellectual Capital and the Enterprise Performance. Bus Eco J 7: 256. doi: 10.4172/2151-6219.1000256

Page 5 of 5

entrepreneurship structural capital, the entrepreneurship innovation capital, the entrepreneurship human capital and the entrepreneurship social capital.

Entrepreneurship enterprises should choose their method to accumulate entrepreneurship intellectual capital according to the actual condition of venture enterprises performance. Research shows that entrepreneurship intellectual capital has a positive effect on entrepreneurship enterprises performance, and different dimension of entrepreneurship intellectual capital has different driving effect on entrepreneurship performance. Entrepreneurship innovation capital, the entrepreneurship human capital and the entrepreneurship social capital all have significantly positive effect on both competitive performance and potential performance. While entrepreneurship structural capital only has significantly positive effect on entrepreneurship competitive performance, but no effect on the entrepreneurship potential performance. Therefore, venture enterprises should accumulate entrepreneurship capital according to their own actual conditions of competitive performance and potential performance.

It's more important to pay attention to entrepreneurship structural capital and entrepreneurship innovation capital. The result of this study shows that entrepreneurship structural capital and entrepreneurship innovation capital have great effect on entrepreneurship intellectual capital, which indicates that enterprises with different intellectual capital has a significant difference in structural capital and innovation capital. So entrepreneurship enterprises should pay more attention to accumulate entrepreneurship structural capital and entrepreneurship innovation capital to achieve the resources' best configuration and product better enterprise performance.

\section{Acknowledgments}

This paper is supported by the youth project of the humanities and socia sciences fund of the Chinese education ministry (No. 09YJC790262), the social science fund of the Hunan province (No. 09YBA162), and the Fundamental Research Funds for The Central Universities of China (No. 105273449)

\section{References}

1. Chang CC, Hung SW, Huang SY (2011) Evaluating the operational performance of knowledge-based industries: the perspective of intellectual capital. Quality \& Quantity 47: 1367

2. Kuo MH, Yang C (2011) Does intellectual capital matter? Assessing the profitability and marketability of IC design companies. Quality \& Quantity 46: 1865-1881.

3. Wang WK, Lu WM, Wang YH (2011) The relationship between bank performance and intellectual capital in East Asia. Quality \& Quantity 47: 1041 . 1062

4. Stewart TA (1997) Intellectual capital: The new wealth of organization Doubleday, New York.

5. Edvinsson L, Malone M (1997) Intellectual capital: Realizing your company's true value by finding its hidden brainpower. Harper Collins Publishers Inc, New York.

6. Jin S (2007)The construction of enterprise intellectual capital management strategic mode. Statistics and Decision 23: 155-156.

7. Stewart TA (1994) Your company's most valuable asset: intellectual capital Fortune 130: 68-74.

8. Roos J, Roos G, Edvinsson L, Dragonetti NC (1998) Intellectual Capital: Navigating in the New Business Landscape. New York University Press, New York.

9. Qiu Y, Pan X, Gu X (2002) Analysis and technology evaluation on intellectual capital. China Soft Science 17: 116-120.

10. Fan $\mathrm{H}$ (2000) Indicators system and quantitative model of knowledge capital appraisal. China Industrial Economy 17: 63-66.

11. Zhang W, Wang C (2007) An empirical research on configuration of entrepreneurial intellectual capital in small and medium high-tech enterprises. Studies in Science of Science 25: 1173-1177.

12. Nahapiet J, Ghoshal S (1998) Social capital, intellectual capital, and the organizational advantage. Academy of Management Review 3: 242-266.

13. Bontis N (1998) Intellectual capital: An exploratory study that develops measures and models. Management Decision 36: 63-76.

14. Bassi LJ, Van Bure ME (2002) Valuing Investment in Intellectual capital. International Journal of Technology Management 18: 414-432.

15. Chen J, Zhu Z, Xie H (2004) Measuring intellectual capital: A new model and empirical study. Journal of Intellectual Capital 5: 195-212.

16. Petty R, Guthrie J (2000) Intellectual capital literature review, measuring reporting and management. Journal of Intellectual Capital 1: 155-176.

17. Shiu HJ (2006) The application of the value added Intellectual coefficien to measure corporate performance: Evidence from technological firms. International Journal of Management 23: 356-365

18. Li G, Liu Z (2008) The correlation analysis of listed companies' intellectual capital performance. Modern Finance and Economics 7: 48-52.

19. Tan HP, Plowman D (2007) Intellectual capital and financial returns of companies. Journal of Intellectual Capital 8: 76-95.

20. Hsu YH, Fang WC (2009) Intellectual capital and new product development performance: The mediating role of organizational learning capability Technological Forecasting \& Social Change 76: 664-677.

21. Sharabati AAA, Jawad SN, Bontis N (2010) Intellectual capital and business performance in the pharmaceutical sector of Jordan. Management Decision 48: 105-131. 